\title{
Syntax, action, comparative cognitive science, and Darwinian thinking
}

\author{
Cedric A. Boeckx ${ }^{1,2 *}$ and Koji Fujita ${ }^{3}$ \\ ${ }^{1}$ Catalan Institute for Research and Advanced Studies (ICREA), Barcelona, Spain \\ 2 Department of General Linguistics, Universitat de Barcelona, Barcelona, Spain \\ ${ }^{3}$ Department of Human Coexistence, Graduate School of Human and Environmental Studies, Kyoto University, Kyoto, Japan \\ *Correspondence: cedric.boeckx@ub.edu
}

Edited by:

Manuel Carreiras, Basque Center on Cognition, Brain and Language, Spain

Reviewed by:

Rie Asano, University of Cologne, Germany

Keywords: syntax, action grammar, modularity, evolution, descent with modification, comparative cognition

\section{A commentary on}

On the similarity between syntax and actions

by Moro, A. (2014). Trends Cogn. Sci. 18, 109-110. doi: 10.1016/j.tics.2013.11.006

The syntax of action

by Pulvermüller, F. (2014). Trends Cogn. Sci. 18, 219-220. doi: 10.1016/j.tics.2014. 01.001

In a recent exchange, Moro (2014) and Pulvermüller (2014) re-open a longstanding debate in the language sciences. Ever since the 1975 Royaumont encounter that set the agenda for linguistics and the classical cognitive sciences, generative linguists, whose ultimate goal we take to be to shed light on the biological basis for language, have rejected any attempt of a rapprochement between natural language syntax and action grammar (motor planning), even if the hierarchical structure of plans is well established in the literature (see already Miller et al., 1960). The parallelism between syntax and action grammar has enjoyed a new lease of life recently (Jackendoff, 2007; Fujita, 2009; Pulvermüller, 2010; Stout, 2010; Arbib, 2012; Knott, 2012), with neuroscientists like Pulvermüller ready to reap the fruits, but Moro reiterates the standard generative stance that the parallelism is at best a metaphor.

Moro usefully lays out two classic arguments against a deep relation between syntax and action: (i) the atomic units these systems manipulate are very different, and (ii) the locality conditions or constraints characteristic of syntax are not found in the domain of action.

We think Moro's arguments fail, for reasons that are worth highlighting, for both sides of the debate: First, the very same arguments Moro puts forth could be raised to argue against a relationship between syntax and other human capacities such as mathematics or music, although here generative linguists have in fact been known to promote such parallelisms, suggesting that they see some underlying similarity despite the differences in terms of lexical units or locality constraints. Because we think that the pursuit of these parallelisms have led to substantial progress (see Patel, 2008 in the domain of music), we don't see why the domain of action should be treated differently.

Second, we think that Moro's classical stance is counterproductive on evolutionary grounds. In fact, it suffers from the same limitations that Gary Marcus points out for classical modularity (Marcus, 2006). Marcus argues forcefully, and persuasively, for the need for a serious injection of Darwinian thinking in the domain of cognitive science, and we would add, especially in the context of generative grammar. Specifically, we think that in his arguments Moro underestimates the benefits of Darwin's great idea of descent with modification. "Descent" thinking is key to construct cognitive phylogenies, and several authors have provided experimental arguments in favor of a relation between syntax and action grammar in this context
(Stout, 2010; Uomini and Meyer, 2013). But as Darwin knew well, descent is often accompanied by modification. Hence we expect differences across related domains. Such differences may in fact obscure deep similarities (cf. the vibrant area of research on deep homologies in current biology). We think that at this point, focusing on the similarities between syntax and action grammar could lead productive work on neurolinguistics, along the lines argued for by Pulvermüller (see Roy et al., 2013 for work on specific language impairment).

In addition, we think that both Moro and Pulvermüller may not be focusing on the most productive mode of comparing syntax and action. Both authors focus on the hierarchical structures in both domains, but we contend that it may be more productive to focus on the generative operation underlying these structures [what Moro refers to as Merge, although we want to keep an open mind about what the relevant elementary computational mechanism(s) may be]. Breaking down the relevant domains into primitive operations would enable the (we think, very real) possibility that the same underlying mechanism is deployed in a variety of cognitive domains, with differences arising from the ways in which these domains are embedded within larger cognitive systems. (Such differences may well be the causes of numerous dissociation effects reported in the modularity literature.) For instance, the fact that natural language syntax manipulates units with conceptual content may account for certain differences between, say, language 
and music, even if the core combinatorial operation is shared by the two systems (Roberts, 2012). Other properties of operations, such as binarity (giving rise to binary branching structures), may be relaxed in domains like arithmetic (Chomsky, 2008) or vision (Jackendoff, 2007), and may therefore be best thought of as domain-specific constraints on the same operation imposed by different interfacing systems.

Finally, as linguists, we would like to point out that the two arguments offered by Moro against a deep relation between syntax and action grammar are somewhat obsolete in the context of current linguistic theorizing. Much current work in syntax has come to view "words" (the atoms of computation that Moro takes to make syntax different) as the output of the syntactic computation, not its input (Halle and Marantz, 1993, and much work in the framework of Distributed Morphology). As for locality conditions, here too syntacticians have come to the conclusion that these may be best seen as constraints acting as post-syntactic filters (see Boeckx, 2012 for a recent survey). So both "words" and "locality" effects may not be so intrinsic properties of natural language syntax (or better said, its core computational process), and should therefore not stand in the way of possible relations across mental capacities of our species.

\section{ACKNOWLEDGMENTS}

The research on which this paper is based was made possible through a Marie Curie International Reintegration Grant from the European Union (PIRG-GA2009-256413), research funds from the Fundacio Bosch i Gimpera, and funds from the JSPS Grants-in-Aid for Scientific Research (A) program (Grant Number 23242025).

\section{REFERENCES}

Arbib, M. A. (2012). How the Brain Got Language: The Mirror System Hypothesis. Oxford: Oxford University Press.

Boeckx, C. (2012). Syntactic Islands. Cambridge: Cambridge University Press.

Chomsky, N. (2008). "On phases," in Foundational Issues in Linguistics, eds C. Otero, R. Freidin, and M.-L. Zubizarreta (Cambridge, MA: The MIT Press), 133-166.

Fujita, K. (2009). A prospect for evolutionary adequacy: Merge and the evolution and development of human language. Biolinguistics 3, 128-153.

Halle, M., and Marantz, A. (1993). "Distributed morphology and the pieces of inflection," in The View from Building 20: Essays in Linguistics in Honor of Sylvain Bromberger, eds K. Hale and S. J. Keyser (Cambridge, MA: The MIT Press), 111-176.

Jackendoff, R. (2007). Language, Consciousness, Culture: Essays on Mental Structure. Cambridge, MA: The MIT Press.

Knott, A. (2012). Sensorimotor Cognition and Natural Language Syntax. Cambridge, MA: The MIT Press.

Marcus, G. F. (2006). Cognitive architecture and descent with modification. Cognition 101, 443-465. doi: 10.1016/j.cognition.2006.04.009

Miller, G. A., Galanter, E., and Pribram, K. H. (1960). Plans and the Structure of Behavior. New York, NY: Holt.

Moro, A. (2014). On the similarity between syntax and actions. Trends Cogn. Sci. 18, 109-110. doi: 10.1016/j.tics.2013.11.006

Patel, A. D. (2008). Music, Language and the Brain. Oxford: Oxford University Press.

Pulvermüller, F. (2010). Brain embodiment of syntax and grammar: discrete combinatorial mechanisms spelt out in neuronal circuits. Brain Lang. 112, 167-179. doi: 10.1016/j.bandl.2009.08.002
Pulvermüller, F. (2014). The syntax of action. Trends Cogn. Sci. 18, 219-220. doi: 10.1016/j.tics.2014. 01.001

Roberts, I. (2012). "Comments and a conjecture inspired by Fabb and Halle," in Language and Music as Cognitive Systems, eds P. Rebuschat, M. Rohrmeier, J. A. Hawkins, and I. Cross (Cambridge: Cambridge University Press), 51-66.

Roy, A. C., Curie, A., Nazir, T., Paulignan, Y., des Portes, V., Fourneret, P., et al. (2013). Syntax at hand: common syntactic structures for actions and language. PLOS ONE 8:e72677. doi: 10.1371/journal.pone.0072677

Stout, D. (2010). "Possible relations between language and technology in human evolution," in Stone Tools and the Evolution of Human Cognition, eds A. Nowell and I. Davidson (Colorado,CO: University Press of Colorado), 159-184.

Uomini, N. T., and Meyer, G. F. (2013). Shared brain lateralization patterns in language and Acheulean stone tool production: a functional transcranial Doppler ultrasound study. PLoS ONE 8:e72693. doi: 10.1371/journal.pone. 0072693

Conflict of Interest Statement: The authors declare that the research was conducted in the absence of any commercial or financial relationships that could be construed as a potential conflict of interest.

Received: 01 April 2014; accepted: 02 June 2014; published online: 27 June 2014.

Citation: Boeckx CA and Fujita K (2014) Syntax, action, comparative cognitive science, and Darwinian thinking. Front. Psychol. 5:627. doi: 10.3389/fpsyg. 2014.00627

This article was submitted to Language Sciences, a section of the journal Frontiers in Psychology.

Copyright $\odot 2014$ Boeckx and Fujita. This is an openaccess article distributed under the terms of the Creative Commons Attribution License (CC BY). The use, distribution or reproduction in other forums is permitted, provided the original author(s) or licensor are credited and that the original publication in this journal is cited, in accordance with accepted academic practice. No use, distribution or reproduction is permitted which does not comply with these terms. 